\title{
Granuloma conjuntival causado por fibras sintéticas
}

\author{
Synthetic fibergranuloma of the conjunctiva
}

Patrícia Maria Fernandes Marback ${ }^{(1)}$

Eduardo Ferrari Marback ${ }^{(1)}$

Fábio Lúcio Borg'es ${ }^{(2)}$

Danilo Cruz Sento Sé ${ }^{(3)}$

Roberto Lorens Marback ${ }^{(4)}$

\begin{tabular}{|l|}
\hline \multicolumn{1}{|c|}{ RESUMO } \\
\hline Objetivo: Relatar caso de granuloma de conjuntiva por fibras sintéti- \\
cas. \\
Relato do Caso: Paciente de seis anos, sexo feminino com história \\
de tumoração em conjuntiva tarsal inferior do olho direito há seis \\
meses. Foi realizada exérese da lesão. O laudo anátomo-patológico \\
mostrou reação inflamatória granulomatosa do tipo corpo estranho \\
com células gigantes multinucleadas fagocitando material \\
birrefringente, compatível com fibras sintéticas. \\
Discussão: O granuloma de fibras sintéticas de conjuntiva é raro \\
e descrito principalmente em crianças, com acometimento unilate- \\
ral, em conjuntiva tarsal inferior ou fundo de saco inferior. O \\
freqüente contato com material de pelúcia nesta faixa etária tem sido \\
apontado como fator etiológico. Granuloma de fibras sintéticas de \\
conjuntiva deve ser considerado no diagnóstico diferencial de lesões \\
tumorais de conjuntiva em crianças.
\end{tabular}

Palavras-chave: Conjuntiva; Granuloma de corpo estranho; Fibras sintéticas
(1) Ex-alunos do Curso de Especialização em Oftalmologia da Faculdade de Medicina da Universidade Federal da Bahia. Atualmente, pós-graduandos em Oftalmologia da Escola Paulista de Medicina, Universidade Federal de São Paulo.

(2) Aluno do $3^{\circ}$ ano do Curso de Especialização em Oftalmologia da Universidade Federal da Bahia.

(3) Professor Auxiliar. Faculdade de Medicina da Universidade Federal da Bahia. Coordenador do Serviço de Oftalmologia do Hospital São Rafael, Fundação Monte Tabor, Salvador - Bahia.

(4) Professor Adjunto Doutor. Faculdade de Medicina da Universidade Federal da Bahia. Chefe do Serviço de Oftalmologia do Hospital São Rafael, Fundação Monte Tabor, Salvador- Bahia.

Endereço para correspondência: Patrícia Maria Fernandes Marback. Av. Dr. Altino Arantes 835, apto 104, Vila Clementino. São Paulo (SP). CEP 04042-034.e-mail: marback@sol.com.br

\section{INTRODUÇ̃̃̃O}

Granuloma de corpo estranho de conjuntiva causado por fibras sintéticas ("teddy bear granuloma") é uma condição rara que acomete principalmente crianças ${ }^{1,2}$. Existem poucos casos publicados na literatura internacional e, de acordo com nosso conhecimento, nenhum caso publicado na literatura nacional. Motivados pela raridade do quadro e pela relevância no diagnóstico diferencial das lesões tumorais de conjuntiva em crianças, relatamos caso de granuloma conjuntival causado por fibras sintéticas.

\section{APRESENTAÇÃO DO CASO}

Paciente do sexo feminino, seis anos, parda, examinada sob n ${ }^{\circ} 476940$ do Serviço de Oftalmologia do Hospital Universitário Professor Edgard Santos, Universidade Federal da Bahia, com secreção amarelada no olho direito, acompanhada de tumor em conjuntiva no mesmo olho há cerca de seis meses. A genitora negou trauma e relatou uso de pomada de tetraciclina por algumas semanas após o início dos sintomas, com melhora parcial da secreção. Ao exame oftalmológico, a visão era de 0,7 em ambos os olhos; à biomicroscopia, apresentava em fundo de saco inferior do olho direito lesão de aspecto vegetante, medindo 4 por 5 milímetros, com pêlos em sua superfície (Fig. 1). O restante do exame oftalmológico encontrava-se sem alterações. Foram feitas suspeitas diagnósticas de granuloma piogênico ou tumor dermóide de conjuntiva. Realizada exérese da lesão sob anestesia 


\section{ANÚNCIO}


geral. O estudo anátomo-patológico revelou numerosos granulomas do tipo corpo estranho, constituídos por células gigantes multinucleadas, fagocitando material birrefringente (material sintético) ao lado de moderado infiltrado linfoplasmocitário e neutrofílico em mucosa conjuntival (Fig. 2).

\section{DISCUSSÃO}

O granuloma de fibras sintéticas de conjuntiva é condição rara que ocorre preferencialmente em crianças, sem história prévia de trauma ${ }^{3,4}$. No entanto, há relato de um caso no qual houve trauma contuso doze anos antes do início da lesão ${ }^{3}$.

É descrito na maioria das vezes como tumoração amarela$\mathrm{da}$, unilateral, em fundo de saco inferior, com a presença de pêlos na sua superfície, tendo como diagnóstico diferencial mais freqüente granuloma piogênico, conjuntivite nodosa ${ }^{5,6}$ ou tumor dermóide de conjuntiva, como no caso hora relatado. Yang e James ${ }^{3}$ descreveram caso em menina de 13 anos que

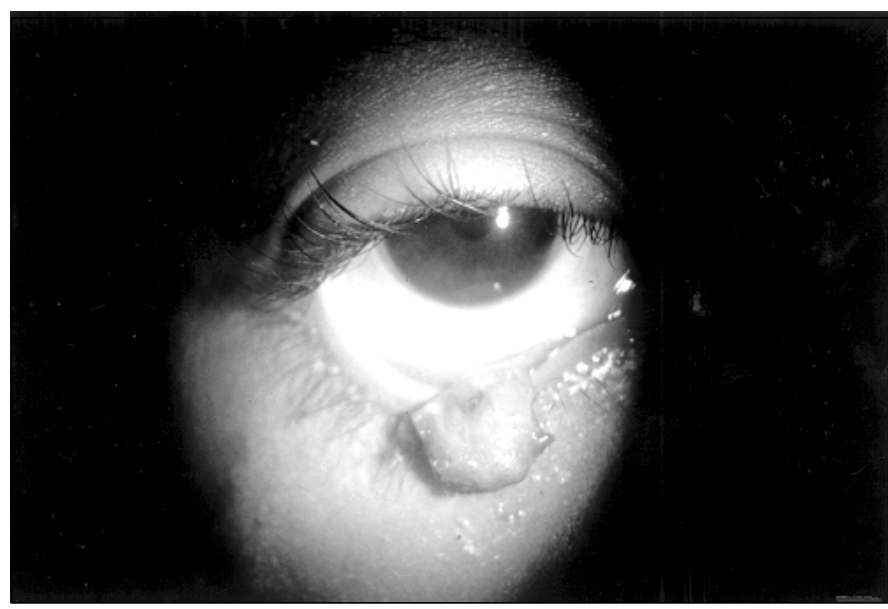

Fig. 1. Lesão tumoral pediculada na conjuntiva palpebral inferior do olho direito.

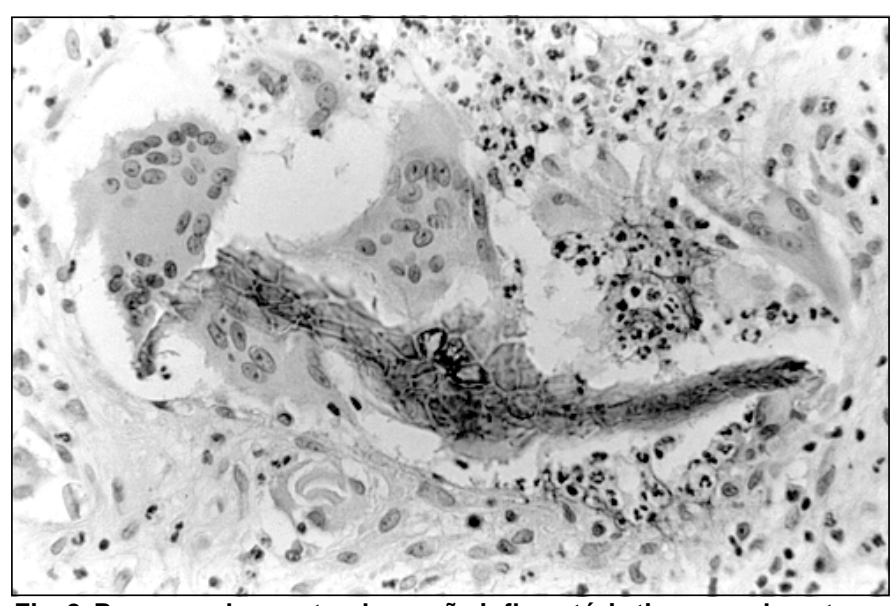

Fig. 2. Presença de acentuada reação inflamatória tipo granulomatosa, contendo numerosas células gigantes multinucleadas ao redor dos fragmentos de corpo estranho. Microfotografia. H.E. 20 × 200. apresentava lesão pigmentada em fundo de saco conjuntival inferior na qual não foram observados pêlos na superfície. Ao exame biomicroscópico observava-se conjuntiva de aspecto normal recobrindo o que parecia ser um emaranhado de filamentos azulados. Neste caso foi feita suspeita diagnóstica de lesão melanocítica ou anomalia venosa.

A idade dos pacientes descritos na literatura varia de 2 a 17 anos, e a preferência por crianças parece estar relacionada com a origem do material sintético. O contato com brinquedos, materiais de pelúcia e cobertores é maior nesta faixa etária, e poderia explicar a inclusão deste material na conjuntiva. Todos os casos revistos na literatura também apresentaram envolvimento do fundo de saco inferior ou conjuntiva tarsal inferior, como nossa paciente.

Lueder e Matsumoto ${ }^{2}$ relataram caso em criança de 4 anos com granuloma de fibras sintéticas de conjuntiva superficial, que foi retirado com bastonete de algodão, sem a necessidade de excisão cirúrgica. $\mathrm{O}$ autor chama atenção para a eliminação do risco da anestesia geral nestas crianças, quando a suspeita diagnóstica é feita precocemente.

O granuloma de fibras sintéticas de conjuntiva é lesão benigna, caracterizada por reação inflamatória tipo corpo estranho, que acomete principalmente crianças. O diagnóstico etiológico só foi confirmado pelo estudo anátomo-patológico. Embora raro, deve ser incluído no diagnóstico diferencial de tumorações da conjuntiva nessa faixa etária.

\section{SUMMARY}

Purpose: To report a case of conjunctival synthetic fiber granuloma.

Case Report: Six-year old female presented with an inferior conjunctival tumor in the right eye for six months. The lesion was excised and histopathological examination revealed granulomatous inflammation and multinucleated giant cells phagocy birefringent material, recognized as synthetic fibers.

Discussion: Synthetic fiber granuloma of the conjunctiva is an uncommon lesion described mainly in children. Usually it occurs unilaterally and situated in the inferior conjunctival fornix. The contact of the eye with toys containing synthetic fibers in this age group could explain the origin of the lesion. Synthetic fiber conjunctival granuloma should be included in the differential diagnosis of conjunctival tumors in children.

Keywords: Conjunctiva; Foreign body granuloma; Synthetic fiber.

\section{REFERÊNCIAS BIBLIOGRÁFICAS}

1. Ferry AP. Synthetic Fiber Granuloma: “Teddy Bear"Granuloma of the Conjunctiva. Arch Ophthalmol 1994;112:1339-41. 


\section{ANÚNCIO}


2. Lueder GT, Matsumoto B. Synthetic Fiber Granuloma. Arch Ophthalmol 1995;113:848-9.

3. Yang YF, James CRH. A Conjunctival Synthetic Fiber Granuloma in a Child Eye 1996;10:143-5.

4. Resnick SC, Schainker BA, Ortiz JM. Conjunctival Synthetic and Nonsynthetic FiberGranulomas. Cornea 1991;10:59-62.
5. Weinberg JC, Eagle RC Jr, Font RL, Streeten BW, Hidayat A, Morris DA. Conjunctival Synthetic Fiber Granuloma. A Lesion that Resembles Conjunctivitis Nodosa. Ophthalmology 1984;91:867-72.

6. Hered RW, Spaulding AG, Sanitato JJ, Wander AH. Ophthalmia Nodosa Caused by Tarantula hairs. Ophthalmology 1988;95(2):166-9.

\section{ANÚNCIO}

